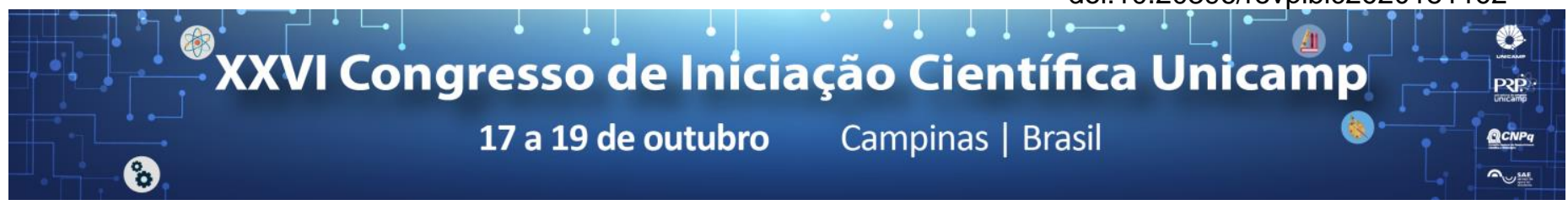

\title{
Manganese residue treatment as a new approach to manganese dioxide production.
}

\author{
Rafael F. Cunha*, Lorrane C. C. B. Oliveira, Leticia F. Cremasco, Gustavo Doubek.
}

\begin{abstract}
Lithium-air batteries performance faces a challenge on the design and development of a functional cathode. Manganese dioxide is a promising material for the air cathode, due to its low cost and ability to catalyse oxygen reactions. In its preparation residues are generated that need to be treated before discard. The present study aims to prepare the manganese dioxide through a precipitation/annealing method, using as raw-material manganese based waste from electrodeposition baths utilized in a previous study, in order to synthesize novel MnOx based electrodes.
\end{abstract}

\section{Key words:}

Manganese dioxide, Materials engineering, Lithium-air batteries.

\section{Introduction}

Electrification of automotive fleet, aligned with the development of sustainable sources of primary energy, rises as a solution to reduce worldwide carbon dioxide emissions without reducing vehicle usage. However, state-of-the-art lithium-ion technology cannot provide a range high enough to fully replace internal combustion engines for batteries. Lithium-air batteries have a theoretical gravimetric energy ( $\mathrm{mWh} / \mathrm{g}_{\text {active material })} 5$ to 8 times higher than that of conventional lithium-ion. The system is based on the reaction between lithium and oxygen to produce a lithium oxide. The technology, however, faces some challenges, among which are large overpotential and low reversibility. In order to overcome these issues, different materials have been studied as catalysts for charge and discharge reactions ${ }^{1}$.

Manganese dioxide has been addressed in literature as a catalyst to oxygen reduction reaction ${ }^{2}$. In a previous study of this same research group, $\mathrm{MnO}_{2}$ based lithium-air batteries electrodes have been prepared by electrodeposition on a stainless-steel net. The technique, although refined, generates residues which must be treated prior to disposal. Poonguzhali et al. (2014) demonstrated the possibility of annealing a precipitated $\mathrm{MnO}_{2}$ to enhance crystallinity and, thus, electric conductivity of the material for supercapacitor applications $^{3}$. The objective of the present study was to adapt and evaluate the precipitation/annealing technique to create electrodes for lithium-air batteries while also treating residues from the previous study.

\section{Results and Discussion}

The bath used for manganese dioxide-electrodeposition contained $\mathrm{Mn}\left(\mathrm{CH}_{3} \mathrm{COO}\right)_{2}$ and $\mathrm{Na}_{2} \mathrm{SO}_{4}$. Under vigorous stirring, sodium hydroxide $(\mathrm{NaOH})$, the precipitating agent of choice, was added until $\mathrm{pH}$ reached 11 . The solution was vacuum filtered to separate the precipitate, $\mathrm{Mn}(\mathrm{OH})_{2}$, from the solution containing other ions. The solid was then dried in oven for 3 hours to obtain manganese hydroxide-powder, which was annealed at $500^{\circ} \mathrm{C}$ for 1 hour to obtain manganese dioxide through combustion, according to the reaction below:

$$
\mathrm{Mn}(\mathrm{OH})_{2}+1 / 2 \mathrm{O}_{2} \rightarrow \mathrm{MnO}_{2}+\mathrm{H}_{2} \mathrm{O}
$$

The synthesized manganese dioxide was mixed with a carbon slurry (carbon Super P $14 \mathrm{~g} / \mathrm{L}$ and PVDF 9,8 g/L in NMP) in a $3: 1$ proportion to carbon, applied in the stainless-steel net surface and let to dry in oven. The prepared electrode was cycled in lithium-oxygen battery, and the result is presented on Image 1.

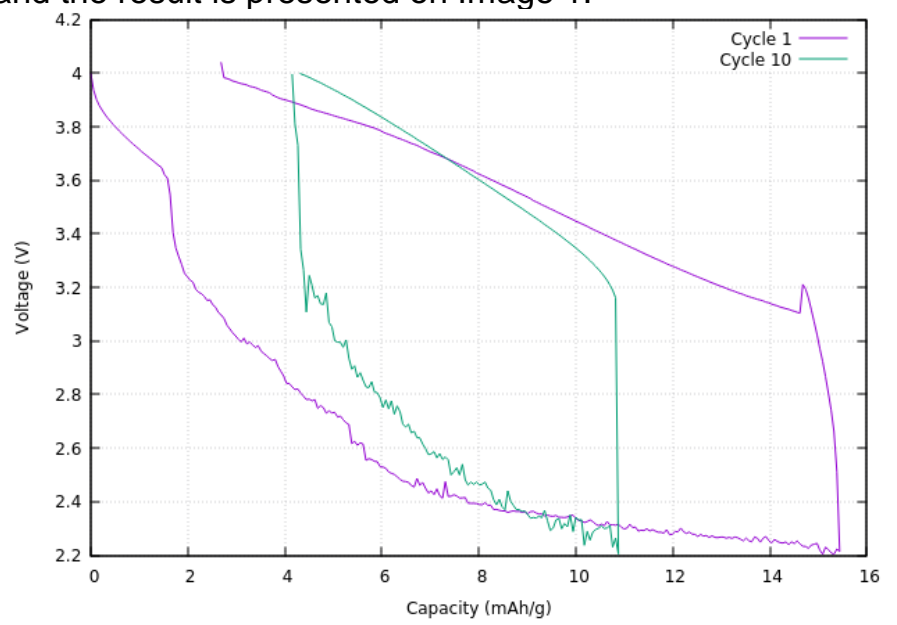

Image 1. Battery performance.

During the first discharge (Cycle 1 in Image 1), there's a plateau formation around 2.3 V. Maximum capacity of a single discharge revolved around $15 \mathrm{mAh} / \mathrm{g}$ active material. A small peak on the beginning of the charge process can be attributed to the material behavior. After 10 cycles, capacity fades to around $11 \mathrm{mAh} / \mathrm{g}_{\text {active material, and }}$ discharge plateau disappears, indicating the formation of material that cannot be decomposed during charge, reducing battery's performance.

\section{Conclusions}

Despite having a low capacity, the manganese dioxide synthesized from the residue showed a promising cyclability, maintaining around $70 \%$ of its capacity after 10 cycles. The catalyst still need improvement, but this study demonstrated that even manganese residues can be used as functional material for lithium-air batteries.

\section{Acknowledgement}

The authors would like to thanks CNPq/PIBIC for the financial support.

1 Wagner, F.; Lakshmanan, B.; Mathias, M. J. Phys. Chem. Lett. 2010, 1, 2204-2219.

2 Mao L. et al.; Electrochimica Acta. 2003, 48, 1015-1021.

${ }^{3}$ Poonguzhali R. et al.; Material Science in Semiconductor Processing. 2014, 27, 553-561. 